\title{
Modal signs and scope relations in TİD
}

\author{
Serpil Karabüklü (Purdue University), Fabian Bross (University of Stuttgart), \\ Ronnie B. Wilbur (Purdue University) \& Daniel Hole (University of Stuttgart) \\ serpilkarabuklu@gmail.com, fabian.bross@ling.uni-stuttgart.de, \\ wilbur@purdue.edu,daniel.hole@ling.uni-stuttgart.de
}

\begin{abstract}
In this paper, we test Bross and Hole's (2017) bodily-mapping hypothesis originally proposed for DGS. They found that operators with high scope (above T) are expressed using physically high articulators (mainly the eyebrows) and lower (IP-internal) categories are expressed manually in German Sign Language. In this way, scope is iconically mapped onto the signer's body (high scope $=$ high articulator; low scope $=$ low articulator). Additionally, they found that descending the scopal height of IP-internal categories, the higher ones (e.g., deontic modality) are concatenated from left to right and the lower ones (e. g., root modality) from right to left. Here, we put the bodily-mapping hypothesis to test by discussing the categories of epistemic (above T), deontic, and root modality (both below T) in Turkish Sign Language. Additionally, we investigate whether concatenation strategies for deontic and root modality differ.

We show that, in Turkish Sign Language, epistemic modality, in contrast to deontic and root modality, requires nonmanual markings with the upper face, in line with the bodily-mapping hypothesis. Turkish Sign Language, however, differs from German Sign Language in that the former requires an additional manual modal sign for epistemic modality. We suggest two modeling possibilities to account for this finding: one assuming base-generation of the modals in their scope-taking position and one based on a movement account.
\end{abstract}

Keywords: modality, Turkish Sign Language, Türk İşaret Dili, bodily-mapping hypothesis, scope

\section{Introduction}

This study is concerned with the expression of epistemic, deontic, and root modality in Turkish Sign Language (Türk İşaret Dili, TİD), a head-final language (Gökgöz 2011), and puts Bross and Hole's (2017) bodily-mapping hypothesis to the test. In Section 2, we briefly introduce the relevant modality terminology, in Section 3, we discuss the bodily-mapping hypothesis, and in Section 4, we briefly outline how the data were collected. In Section 5, we discuss data from TID and compare them to the data from German Sign Language (DGS) (which is mixed-headed (Bross and Hole 2017)). The nonmanuals used with the three different modal flavors are discussed in Section 6. Section 7 presents a brief outline of two competing accounts to model the findings. In Section 8, we conclude. 


\section{Modality: modal force and modal flavors}

Modality is a term used to describe the speaker's determination based on evidence about a proposition as being possible or necessary (modal force) (Kratzer 1981; Palmer 2001). In many languages of the world, including English, modal force is lexicalized. In English, for example, the modal can is specified for possibility (1a) and the modal must is specified for necessity (1b). When a speaker uses can, it means that there is (at least) one situation in which what the speaker asserts could be true (quantificationally, an existential), whereas when a speaker uses must, it means that in all situations what the speaker asserts should be true (quantificationally, a universal). Thus, modal force refers to the strength of the likelihood of the speaker's assertion being true (in at least one or in all situations).
(a) The light is on. Paul can be at home early.
(b) The light is on. Paul must be at home.

epistemic mod. (possibility)

epistemic mod. (necessity)

There is, however, another dimension of modality, namely the respect in which something is a necessity or a possibility (modal flavor). Lexicalization of modal flavors can vary among languages. It is unclear how many different modal flavors have to be distinguished, but here we distinguish three: epistemic, deontic, and root. Epistemic modality refers to what can or must hold in view of what a speaker knows; deontic refers to what can or must hold with respect to relevant asymmetric power relationships; and root refers to what can or must hold in view of the inherent properties of the subject (their capabilities, in the case of root possibilities). Examples are given in (2).

(a) The light is on. Paul must be at home.

epistemic mod. (necessity)

(b) Paul's parents are strict. Paul must be at home early.

deontic mod. (necessity)

(c) Paul can perform magic.

root mod. (possibility)

Differences among the different modal flavors are not only reflected in their semantic scope, but are also mirrored in syntax, to be more precise, in syntactic height. While epistemics scope above tense (discussed below), deontic and root modals scope below tense (with deontic structurally higher than root). These scopal relations can be best demonstrated by comparing epistemic and deontic modality. The example in (3) from Wurmbrand $(2001,184)$ shows that the German modal verb müssen 'must' can have either an epistemic or a deontic interpretation (indicated by translations).

$$
\begin{aligned}
& \text { Sue muss zuhause arbeiten. } \\
& \text { Sue must at-home work } \\
& \sqrt{ } \text { 'It must be the case that Sue is working at home.' } \\
& \checkmark \\
& \checkmark
\end{aligned}
$$

epistemic deontic

Although the expression of epistemic and deontic here does not differ lexically, it can be shown that epistemics are located above tense whereas deontics are located below tense in German. This can be seen when a tensed auxiliary is added to a sentence containing a modal, because in this case only the deontic reading survives $(4$, Wurmbrand $(2001,184))$.

Sue hat zuhause arbeiten müssen.

Sue had at-home work must

* 'It must have been the case that Sue is working at home.'

epistemic

$\checkmark$ 'Sue had an obligation to work at home.'

deontic 
With two syntactic positions for the modals, epistemic above tense and deontic below, there are two possible interpretations of the sentence without auxiliary in (3), but only the lower deontic reading when the tensed auxiliary is present in (4). To get the lower deontic reading, the deontic modal must scope below tense; the upper epistemic scope reading is blocked.

\section{Hypotheses: Bross and Hole (2017) on German Sign Lan- guage}

In their study on German Sign Language (DGS), Bross and Hole (2017) focus, in the spirit of Cinque (1999), on the possible universal ordering of syntactic categories on the clausal spine. They claim that there is a general split between the expression of categories above and below tense in DGS. While the categories above tense are expressed nonmanually, the categories below tense find manual expression (they do not claim that everything above $\mathrm{T}$ cannot be expressed manually, but that there always needs to be a non-manual component for the categories above T). They hypothesize that scopal height is iconically mapped onto the signer's body and conjecture that this principle may turn out to be a sign language universal: The higher the scope of an operator, the higher the body part used for its expression. Descending the clausal spine thus should mean descending the body in sign languages. By looking at the categories of speech-acts, evaluation, epistemic modality, scalarity, volition and deontic and root modality, they show that the highest categories, namely speech-acts, evaluation, and epistemic modality, are marked with the eyebrows; the next lower category, scalarity, is marked lower, using the cheeks. Further descending the clausal spine and crossing tense, the lower categories, volition, deontic and root modality, find manual expression. Bross and Hole (2017) claim that the different syntactic heights of each of these three lower categories find overt realization in DGS through different concatenation strategies: While volitional verbs like PLAN or WISH systematically occur to the left of the vP in DGS (they 'concatenate from left to right' in their terminology), the position of deontic modals seems to vary (pre- or post-verbal), and root modals naturally occur in a position following the vP (i. e., root modals are expressed by a right-to-left concatenation strategy). Taken together, DGS presents the following pattern (tense added for orientation) (5).

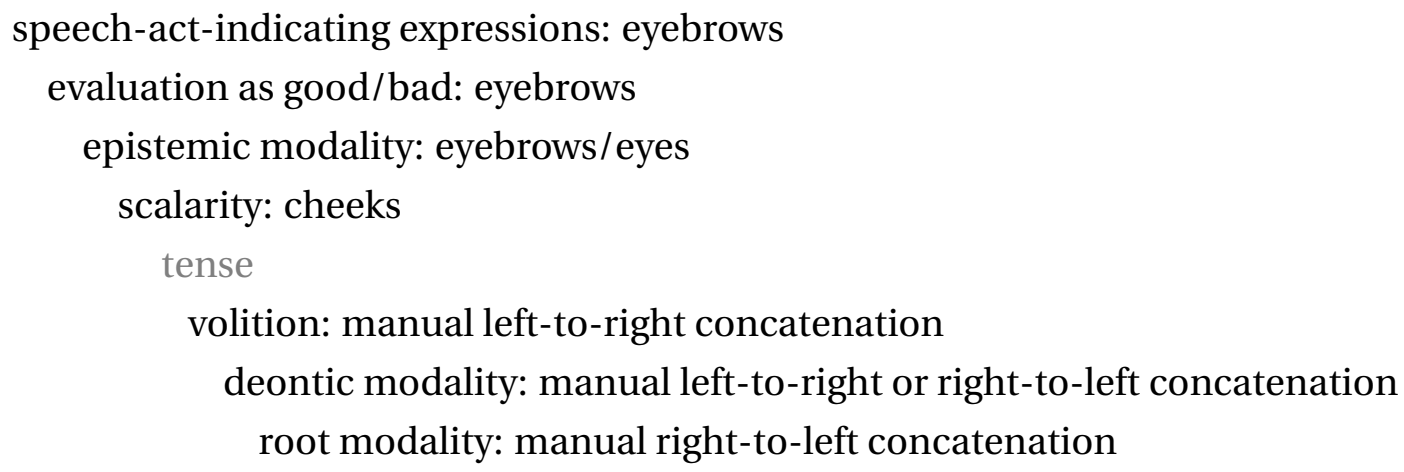

Bross and Hole's (2017) findings can be summarized as follows: epistemic modality is expressed nonmanually (upper face) only. The use of modal verbs in epistemic contexts is disallowed in DGS, while nonmanual markings are obligatory in epistemic contexts. Nonmanual markings are not obligatory with deontic or root modals. Thus, modal categories below tense are expressed manually only. This implies that whatever nonmanuals might occur on these lower modals would come from a different source, such as signer evaluation and scalarity, as we will suggest below. 
From their data, Bross and Hole (2017) derive two hypotheses, one they claim may hold universally and one language-specific:

- The bodily-mapping hypothesis: Scope is iconically mapped onto the body; higher categories expressed with physically higher body-parts.

- Concatenation behavior differs according to scope: Categories below tense find manual expression in DGS with intermediate IP-internal categories (e. g., bouletic and deontic modality) concatenating from left to right and lower IP-internal categories (e.g., root modality) concatenating from right to left; the concatenation behavior is not claimed to be universal, but probably subject to cross-linguistic variation.

In the following, we test if epistemic modality as a category above $\mathrm{T}$ also finds nonmanual expression with a physically high articulator in TİD (as would be expected from the bodilymapping hypothesis) and investigate whether the two lower modal flavors (deontic and root modality) are expressed using different concatenation strategies in TİD as for DGS.

\section{TíD data}

To test these hypotheses, 4 adult female Deaf signers in İstanbul were interviewed using the stimuli from Bross and Hole (2017). 2 were interviewed again a year later. The stimuli were initially translated into Turkish and discussed with an interpreter. Then, contexts for each target sentence were created for the interviews. There were 2 target sentences for each category; epistemic, deontic, permission, and ability modality (8 in total). There were also contexts where the degree of possibility (4) or necessity (4) was manipulated to observe the distinction between POSSIBLE and NECESSARY, so 18 target sentences in total. However, the sessions were discussions through contexts between the participants and the interpreter. Thus, the final elicited sentences are 37 for possibility, 12 for necessity, 7 for permission, and 3 for ability. There were no fillers because this study was the first phase of the research to observe the basics of modals in TİD.

Signers were asked how they would sign the target sentence in the given context and whether the target sentence is felicitous in that context. If it was infelicitous, they were asked to provide another sentence to fit the context. Furthermore, they were also asked whether different word orders in the target sentence were acceptable. If so, they were asked whether there are meaning differences with the different orders. After interviews, the recordings were transcribed in ELAN. Data were analyzed in terms of matching of the context and the target sentence, constituent order, and nonmanuals occurring with the modal signs and their spreading domains.

\section{Modal signs in TíD}

There are a few studies on TIDD modal root or deontic signs: POSITIVE (ability), FREE (permission) and OBLIGED (obligation) (Dikyuva, Makaroğlu, and Arık 2017); NECESSARY (necessity) (Gökgöz 2009; Özkul 2016; Dikyuva, Makaroğlu, and Arık 2017) and HAVE TO (obligation, necessity) (Gökgöz 2009). In fact, there is a brief mention of epistemic in Gökgöz (2009) and testing NECESSARY in epistemic contexts by Özkul (2016). This study will approach modals in light of Bross and Hole (2017)'s hypothesis. We focus on POSSIBLE, NECESSARY, FREE, DO, and POSITIVE. In terms of modal flavor, POSSIBLE has epistemic uses whereas NECESSARY 
Figure 1: Modal signs observed in this study.

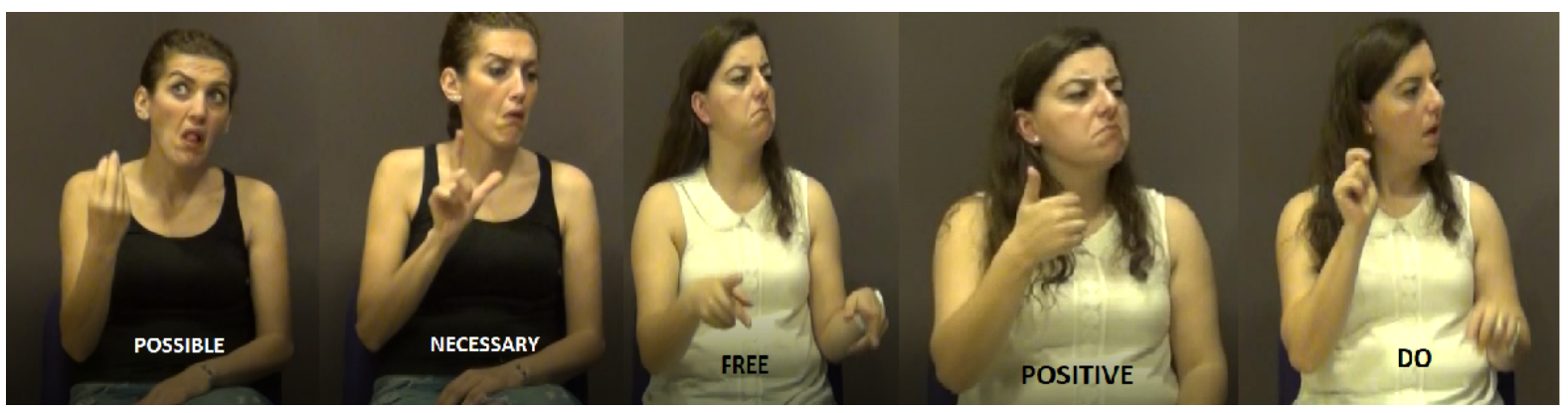

and FREE have deontic uses. DO and POSITIVE are lexically specified for root modality. These modals are given in Figure 1.

In the following, we discuss the expression of epistemic, deontic, and root modality in TİD to test Bross and Hole (2017)'s hypotheses. In contrast to DGS which conveys epistemic modality primarily by use of nonmanuals (6), ${ }^{1}$ TID requires the use of a manual sign alongside nonmanual markers (8). For DGS, sentence (6) will still have epistemic flavor when the sentential adverb PROBABLY is omitted from the sentence, and manual modal verbs (i.e., MUST or CAN) are generally disallowed in epistemic contexts (7). As far as we know, sentence (9) cannot have a(n epistemic) modal interpretation if the sign POSSIBLE is omitted, in contrast to DGS example (6).

$\frac{\text { br,hn }}{\text { (PROBABLY) SWEN WORK }}$ GO $_{1}$,

(Bross and Hole 2017, p.23)

$$
\text { IX }_{3 \mathrm{a}} \text { LIGHT THERE *PETER AT-HOME MUST }
$$

'The light is on. Peter must be at home.'

(Bross 2018, p.194)

(8) Light-ON EXISTENTIAL MOM HOME EXISTENTIAL POSSIBLE 'The light is on. My mom may be at the home.'

(9) LIGHT-ON EXISTENTIAL *MOM HOME EXISTENTIAL

'The light is on. My mom may be at the home.'

As seen in sentences (6) and (8), even though TíD requires a manual sign for the epistemic, the nonmanuals eye squint and head tilt are both present and spread over the whole clause, similar to the nonmanuals in DGS. This observation is in line with the idea that categories above $\mathrm{T}$ find nonmanual expression with a high articulator. Additionally, being high up the tree structure means that it is possible for the NMMs to spread over their c-command domain (Wilbur 2000). Thus, TİD requires both the manual sign POSSIBLE, for modal force, and

\footnotetext{
${ }^{1}$ Abbreviations for nonmanuals in the article are: es-eye squint, eo-eyes open, ht-head tilt, br- brow raise, hn-head nod, bs-brow scrunch, bf-brow frown, hb-head back, no nmm-no nonmanuals. Head nod contains both single and repetitive head nods.
} 
epistemic nonmanuals indicating modal flavor. A detailed description of the nonmanuals used in epistemic contexts will be discussed in Section 6 .

While deontic modals can appear to the left or the right of the vP in DGS (10) (Bross and Hole 2017), in TİD deontic modals are only allowed postverbally, as shown for NECESSARY in (11). Example (12) illustrates that it is not possible for a deontic modal to precede the vP in TİD. Thus, no left-to-right sequencing occurs at this level in TİD .

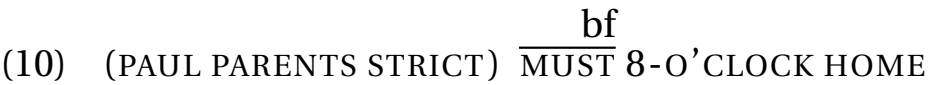

'(Paul's parents are strict.) Paul has to be at home at 8 o'clock.' (Bross and Hole 2017, p.28)

(11) THURSDAY COME NECESSARY

'He must come on Thursday.'

(12) *THURSDAY NECESSARY COME

'He must come on Thursday.'

The ungrammaticality in (12) shows that TİD only has right-to-left sequencing whereas DGS has both options - left-to-right and right-to-left. As Bross and Hole (2017) pointed out, languages may differ in this respect. Likewise, similar to the lower operators in DGS (13), lower operators in TİD are also realized in right-to-left sequencing (14).

As seen in (13), when DGS CAN occurs post-verbally, it receives a root (ability) interpretation (not a deontic one). Similarly, TİD has lower operators, like POSITIVE or DO, in postverbal position. As shown in Figure 1, POSITIVE and DO are different signs, yet both can appear in ability contexts separately or together; we must leave their similarities and differences for another study.

(13) MIRACULIX PERFORM-MAGIC CAN

'Miraculix can perform magic.'

(Bross and Hole 2017, p.29)

(14) KADIR MAGIC POSITIVE/DO ${ }^{2}$

'Kadir can perform magic.'

The idea that modals in TİD take scope from right to left is supported by the observation that when two modals occur in one clause, the one on the right has higher scope than the one on the left, illustrated in examples (15) and (16) from Özkul (2016). Example (15) shows that the higher epistemic modal POSSIBLE follows the deontic modal NECESSARY. Similarly, the higher deontic modal NECESSARY occurs after the ability CAN in (16). Note that the sentences become ungrammatical when the order of modal signs is changed.

(15) CHILD BRING NECESSARY POSSIBLE

(TİD; Özkul 2016, p.19)

'It may be the case that she must bring her child.'

(16) IX $_{3}$ CAR-DRIVE CAN NECESSARY

'It is epistemically necessary that he can drive.'

(TİD; Özkul 2016, p.19)

\footnotetext{
${ }^{2}$ We have observed both POSITIVE and DO during the sessions. We do not yet have enough evidence to draw the difference between them for now. This is why we will report both of them.
} 
Another difference between DGS and TIDD is how permission and ability meanings are conveyed. DGS uses the same lexical sign in different syntactic positions whereas TIDD uses different lexical signs. DGS can use the sign CAN for both permission (pre-verbal) (17) and ability (post-verbal) (18), whereas TIDD has separate signs for each meaning, FREE for permission (19) and POSITIVE/DO for ability (20). We acknowledge that another language may have one morpheme that appears in the same syntactic position for these different meanings. TID is a strict head final language and has different lexical items for the different modals (Gökgöz 2011). On the other hand, DGS is observed to be mixed headed (Bross and Hole 2017) and allows the modal to appear in different positions for different modal flavors.

(LISA PARENTS EASY) CAN UNTIL 12-O'CLOCK AWAY '(Lisa's parents are not strict.) She is allowed to stay until 12 o'clock.'

(Bross and Hole 2017, p.28)

(18) MIRACULIX PERFORM-MAGIC CAN

'Miraculix can perform magic.'

(Bross and Hole 2017, p.29)

(19) NIGHT a IX

'Bulut can hang out till 12 at night.'

(20) KADIR MAGIC POSITIVE/DO

'Kadir can perform magic.'

So far we see that TİD differs from DGS in that it requires manual modals not only for the lower modal flavors, but also for epistemic modality scoping above tense. Nonetheless, TID is similar to DGS in that it also requires the use of upper-face nonmanuals in epistemics. Further, TIDD does not require nonmanuals in deontic and root contexts (although other evaluations may additionally be marked nonmanually, but are, crucially, not obligatory). An additional difference between TID and DGS concerns the sequencing of modals. While the direction of sequencing in DGS depends on the modal flavor, in TİD modals strictly scope from right to left. We suggest that this may result from the fact that TIDD is strictly right-headed.

\section{Nonmanuals occurring with modals}

Further attention needs to be paid to nonmanuals in TİD. As a higher operator, the epistemic in DGS is realized through nonmanuals, brow raise and head nod (6). TID also has nonmanuals occurring with the epistemic sign POSSIBLE (8). Before focusing on the epistemic, we give an overview of nonmanuals in deontic and root contexts (Table 1 and 2). The source of nonmanuals with modals (context, lexical item or information structure) is not always clear, due to lack of studies on information structure and topic or focus in TID. Yet, from Table 1, we can observe that the nonmanuals with root modals are consistent, using lips and cheeks. ${ }^{3}$ Furthermore, when used in these contexts, the nonmanuals do not generally spread, unlike nonmanuals occuring with epistemics. As seen in Table 1, they are not always required to occur with the manual sign. Nonmanuals with root modals may result from scope of higher

\footnotetext{
${ }^{3}$ We have observed both POSITIVE and DO in ability contexts (20); however, Do does not always occur with nonmanuals. When it has nonmanuals, they are head nod and brow raise. Unlike FREE and POSITIVE, it has nonmanuals from the upper face. Furthermore, we are not certain whether it conveys the truth of assertion rather than being a part of the assertion, or it conveys characteristics of the subject. With these concerns and the need of further study, we left out Do from Table 1.
} 
nonmanual operators, such as the signer's evaluation or perspective on scalarity since the semantics of root and deontic modals are prone to gradability.

Table 1: Nonmanuals with FREE (permission) and POSITIVE (ability)*

\begin{tabular}{lllll} 
Manual/NMMs & lips purse & cheek puff & brow scrunch & brow frown \\
\hline FREE & $83.33 \%$ & - & $50.00 \%$ & $33.33 \%$ \\
\hline POSITIVE & $81.66 \%$ & $45 \%$ & - & -
\end{tabular}

${ }^{*}$ Nonmanuals co-occur so the total may be more than $100 \%$.

In contrast, POSSIBLE and NECESSARY appear with more varied nonmanuals than the root modals. Nonetheless, epistemic and deontic flavors show a pattern. The hand configuration of the sign NECESSARY can occur both in epistemic and deontic contexts. We will refer

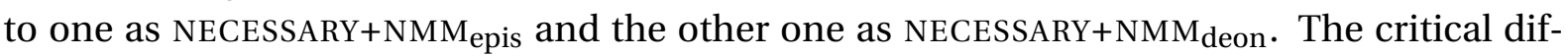
ferences between these two is the nonmanuals. NECESSARY+NMMepis takes the same nonmanuals as other epistemics, such as POSSIBLE, and permits spreading over the clause (Section 5). In contrast, NECESSARY $+\mathrm{NMM}_{\text {deon }}$ has different nonmanuals (Table 2) which, like the root modals, does not generally spread. We consider NECESSARY+NMM $M_{\text {deon }}$ and NECESSARY+ $\mathrm{NMM}_{\text {epis }}$ to be compositional (a root plus deontic nonmanuals and a root plus epistemic nonmanuals, respectively) where the manual sign is the modal force and the nonmanual markers are the modal flavors. ${ }^{4}$

Evidence that NECESSARY $+\mathrm{NMM}_{\mathrm{epis}}$ is epistemic is that the signers found it acceptable in contexts like the following: You will meet with Sumru and you know that it is her office hour. She should be in her office. You checked her office and she is not there, then you have to guess where she is (21).

\section{SUMRU ROOM WORK ROOM NONEXISTENTIAL, IX TIME ROOM BE NECESSARY PALM-UP, es,ht}

SECRETARY WORK ROOM GO NECESSARY

'Sumru is not in her office. She should (deontic) be in her office now. She might (epistemic) be in the secretary's office.'

In this context, the signer is able to eliminate certain options: Sumru is obliged to be in her office due to school regulations, therefore she is likely to be in her office; not in her office, therefore likely to be in the secretary's office. Thus, the signer knows that other possibilities do not hold based on the information in the context.

What we have in (21) is a strong epistemic flavor that is expressed by the nonmanuals while the modal force expressed by the hands is universal. How do we know that we have universal force and epistemic flavor? In this context, with the strong evidence available to the signer, POSSIBLE (existential) is dispreferred and NECESSARY $+\mathrm{NMM}_{\mathrm{epis}}$ (universal) is preferred.

Furthermore, you cannot put NECESSARY+NMM $\mathrm{Npis}_{\text {in }}$ in contexts where universal force is not supported. For example, in (22), NECESSARY $+\mathrm{NMM}_{\mathrm{epis}}$ is not acceptable because this context has just one piece of information - that is, the light is on. We can imagine other possibilities like 'Someone else is at the home.' or 'Mom forgot the light on and left the

\footnotetext{
${ }^{4}$ Note that we do not propose that there are two different lexical signs of NECESSARY for epistemic and deontic. We just labelled it as NECESSARY $+\mathrm{NMM}_{\text {epis }}$ and NECESSARY+NMM deon to be able to present the discussion clearly.
} 
house.' and so on. The evidence 'The light is on' gives us only one possible world, thus universal force is not available. This is because universal force requires the proposition to hold in every possible world.

*LIGHT-ON EXISTENTIAL MOM HOME EXISTENTIAL NECESSARY+NMM $\mathrm{Mpis}$ 'The light is on. My mom must be at home.'

Modal force comes from the manual part of the sign; so then how do we get the epistemic flavor? Compare the nonmanuals occurring with POSSIBLE (existential force) (23), NECESSARY+ $\mathrm{NMM}_{\text {epis }}$ (universal force) (24) and NECESSARY+NMM deon (universal force) (25). POSSIBLE (23) and NECESSARY+NMM $\mathrm{N}_{\text {epis }}(24)$ have the same higher face nonmanuals and they can spread over the clause. In contrast, NECESSARY (25) has different nonmanuals, and they behave like nonmanuals on the root modals FREE and POSITIVE with limited spreading, basically over the sign itself. Thus, we propose that NECESSARY $+\mathrm{NMM}_{\mathrm{epis}}$ is the combination of the manual sign NECESSARY that preserves its universal force, and the nonmanuals, eye squint and head tilt that give epistemic modal flavor.

es,ht
'She may be in her office.'

$$
\begin{aligned}
& \text { es, hn } \\
& \text { 'SX IX-POSS }{ }_{3} \text { OFFICE EXISTENTIAL NECESSARY+NMM } \\
& \text { 'Shis }
\end{aligned}
$$

(25) IX $_{3}$ IX-POSS 3 OFFICE EXISTENTIAL $\overline{\text { NECESSARY+NMM deon }}$ 'She must (deontic) be in her office.'

Bearing this discussion in mind, the pattern in Table 2 becomes clear when we distinguish nonmanuals occurring with NECESSARY $+\mathrm{NMM}_{\text {epis }}$ from the ones with NECESSARY $+\mathrm{NMM}_{\text {deon }}$. If one pays attention closely to the eyes, they are in total contrast: eyes are squinted with NECESSARY+NMM $M_{\text {epis }}$ whereas they are open with NECESSARY ${ }_{\text {deon }}$. A further step is to compare the eyes in NECESSARY+NMM $M_{\text {epis }}$ and in POSSIBLE : both have (upper face) eye squint

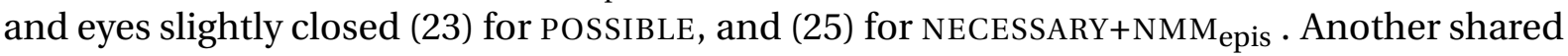
nonmanual in POSSIBLE and NECESSARY $+\mathrm{NMM}_{\text {epis }}$ is head tilt. Nonmanuals in the corpus also support the proposal for NECESSARY+NMM $\mathrm{Npis}_{\text {in }}$ in epistemic context (24) being the combination of hands from NECESSARY with epistemic nonmanuals eye squint and head tilt.

Table 2: Nonmanuals with POSSIBLE and NECESSARY*

\begin{tabular}{lllllllll} 
Manual/NMMs & eyes & ht & br & hn & bs & bf & hb & no nmm \\
\hline POSSIBLE & es $42 \%$ & $14 \%$ & $11 \%$ & $9 \%$ & $3 \%$ & $3 \%$ & - & $39 \%$ \\
\hline NECESSARY+NMM epis & es $32 \%$ & $3 \%$ & $19 \%$ & $18 \%$ & $13 \%$ & $29 \%$ & - & $19 \%$ \\
\hline NECESSARY+NMM deon & eo $11 \%$ & - & $37 \%$ & $21 \%$ & $21 \%$ & - & $11 \%$ & $21 \%$ \\
\hline & *Nonmanuals co-occur so the total may be more than $100 \%$.
\end{tabular}

When we return to Bross and Hole's (2017) mapping with regard to nonmanuals occurring in epistemic contexts, we can argue that TİD also has (upper face) nonmanuals for epistemic 
flavor. Their spreading domain further shows that they are high in the hierarchy so that they scope over the clausal domain. This is the case with both epistemic (23) and universal force (24). To summarize this section, the nonmanuals with root modals are lower face nonmanuals that spread over the manual sign, which is appropriate to their lower operator status. On the other hand, epistemic nonmanuals spread over the clause and can combine with both manual signs POSSIBLE and NECESSARY. Thus, epistemic nonmanuals form a morphemic bundle and sit in a high position in the hierarchy. In this respect, TID is similar to DGS, yet TİD requires a manual sign to occur with the epistemic nonmanuals while DGS does not. One further possible difference is that in TİD, upper face nonmanuals, specifically the eyes, are involved in distinguishing epistemic and deontic flavors, with eyes squinted for epistemic and eyes open for deontic. Based on Bross and Hole (2017), we expected to find lower face marking for deontic.

\section{Why is TíD different from DGS?}

So far, we have shown that TID, in contrast to DGS, requires the use of a manual modal in epistemic contexts along with the epistemic nonmanuals. The question now is where this difference comes from. Following Bross and Hole (2017) we assume that the nonmanuals encode modal flavor while the manual signs encode modal force.

One solution following Cinque (1999) would be to assume that modals are base-generated in their respective positions. Under this assumption, the manual modals (the force markers) are simply phonetically null in epistemic contexts in DGS but are overt in TİD.

Another solution is the possibility that DGS and TIDD differ in the timing of operator movement for epistemics. In such a scenario, epistemic modal force enters the derivation below $\mathrm{T}$ in both languages. Raising occurs pre-spell out in DGS, and after spell out in TiD. Such a solution might be supported by the absence of epistemic readings in sentences with overt tensed auxiliaries as seen in (4). If Bross and Hole (2017) are right in saying that all categories above $\mathrm{T}$ are expressed nonmanually in DGS, then this simply means that manual epistemic modal force markers cannot be articulated after movement to their above-T position. The head and the face have no hands, hence the manual modal cannot be articulated in its high landing site. The grammar formalism that we adopt here forces us to assume a phonetically empty variant of a modal force marker for this case, one that doesn't make the $\mathrm{PF}$ representation crash if the modal force marker receives no pronunciation/articulation.

Both solutions present remaining questions. In the first, it would need to account for the finite status of epistemics because they are above T. The second would need to identify what would block overt movement of the epistemic force to its higher position in TİD.

\section{Conclusion}

We have explored Bross and Hole's (2017) bodily mapping hypothesis in TİD to test its universality. In line with the hypothesis, both DGS and TIDD require the use of upper-face nonmanuals for expressing epistemic modality. Yet, DGS and TID have differences in deontic and root modals. DGS has manual signs whereas TID has upper face nonmanual for deontic and lower face nonmanuals for root modals (which optionally show a variety of nonmanuals). In addition to nonmanuals in epistemic contexts, TİD requires also a manual sign while DGS disallows a manual modal verb. The main question is how this difference can be captured. One possibility we discussed is that modal verbs are base-generated in their 
respective scope-positions. Another possibility we discussed is that it may be the case that modals move from a lower position to their higher scope-taking position at different points in the derivation in DGS and TID. As stated in the previous section, both solutions need to account for some remaining questions.

In terms of left-to-right and right-to-left sequencing, TİD, unlike DGS, has strict right-toleft sequencing that is also supported in contexts where there is a sequence of two modals (Özkul 2016). The reason for this difference might be tracked to the difference in the syntax of two languages. That is, DGS is mixed headed (Bross and Hole 2017) whereas TID is strictly head final (Gökgöz 2011). It can be proposed that TİD also has different lexical signs for different modal readings due to its being head final.

\section{Acknowledgments}

We want to thank all the participants in this study. This study is partially funded by National Institutes of Health grants R01 DC 014498 and WIRCO for Ronnie B. Wilbur and Serpil Karabüklü.

\section{References}

Bross, Fabian. 2018. “The clausal syntax of German Sign Language: A cartographic approach”. PhD thesis, Stuttgart University.

Bross, Fabian, and Daniel Hole. 2017. "Scope-taking strategies and the order of clausal categories in German Sign Language”. Glossa: a Journal of General Linguistics 2 (1:76): 130.

Cinque, Guglielmo. 1999. Adverbs and functional heads. A cross-linguistic perspective. Oxford: Oxford University Press.

Dikyuva, Hasan, Bahtiyar Makaroğlu, and Engin Arık. 2017. Turkish Sign Language grammar. Ankara: Fersa Ofset.

Gökgöz, Kadir. 2009. “Topics in Turkish Sign Language (Türk İşaret Dili)”. MA thesis, Boğaziçi University.

— . 2011. "Negation in Turkish Sign Language: The syntax of nonmanual markers". Sign Language and Linguistics 14 (1): 49-75.

Kratzer, Angelika. 1981. "The notional category of modality". In Words, worlds, and contexts. New approaches in word semantics, ed. by Hans J. Eikmeyer and Hannes Rieser, 38-74. Berlin: Mouton de Gruyter.

Özkul, Aslı. 2016. "Deontic and epistemic necessity in Turkish Sign Language”. Unpublished manuscript.

Palmer, Frank. 2001. Mood and modality. Cambridge: Cambridge University Press.

Wilbur, Ronnie B. 2000. "Phonological and prosodic layering of nonmanuals in American Sign Language”. In The Signs of Language revisited: An anthology to honor Ursula Bellugi and Edward Klima, ed. by Harlan Lane and Karen Emmorey, 215-244. Mahwah: Erlbaum.

Wurmbrand, Susanne. 2001. Infinitives: Restructing and clause structure. New York: Mouton de Gruyter. 